\title{
Pemahaman Penerjemahan Bagi Guru Bahasa Jepang di Wilayah 3 Cirebon dan Jabodetabek
}

\section{Rainhard Oliver Hoftman', Anggiarini Arianto², Siti Nur Isnaini', Rosi Novisa Syarani ${ }^{4}$, Yanti Hidayati ${ }^{5}$}

\author{
Sekolah Tinggi Bahasa Asing JIA $\mathbf{1}^{\mathbf{1}, \mathbf{3}, \mathbf{4}, \mathbf{5}}$ \\ Korespondensi: rainhard.ohw@stba-jia.ac.id ${ }^{1}, \underline{\text { anggiarini.a@ } \text { stba-jia.ac.id }}{ }^{2}, \underline{\text { siti.ni@ @tba-jia.ac.id }}$, \\ rosi.ns@stba-jia.ac.id ${ }^{4}$, yantihidayati@gmail.com ${ }^{5}$
}

\begin{abstract}
This community service activity aims to provide knowledge about translation and stimulus to Japanese language teachers who teach in schools in Jabodetabek and Cirebon region 3 through the Musyarawah Guru Mata Pelajaran (MGMP). There are 19 senior high schools that take part in this PkM. From this PkM activity, it is expected that Japanese language teachers can impart their knowledge to their students. The Material used in this activity was taken from the Japanese language proficiency test level 4 section of dokkai (reading comprehension). This study uses a collaborative approach, where activities are divided into groups in solving problems. Collaborative learning is used so that each group member is actively involved in providing ideas for the problems that occur. The results of this PkM activity is the input of Indonesia words from one Japanese word, especially for words that have cultural elements. Agreement and acceptance of the words used are important points in this PkM activity.
\end{abstract}

Keywords: collaborative, MGMP, translations

\begin{abstract}
Abstrak
Kegiatan pengabdian kepada masyarakat ini bertujuan untuk memberikan pengetahuan tentang penerjemahan dan stimulus kepada guru-guru bahasa Jepang yang mengajar di sekolah-sekolah Jabodetabek dan wilayah 3 Cirebon melalui Musyarawah Guru Mata Pelajaran atau disingkat MGMP. Terdapat 19 sekolah menengah atas yang mengikuti PkM ini. Dari kegiatan PkM ini diharapkan guru-guru pengajar bahasa Jepang dapat mentranfer pengetahuannya kepada siswa siswi didikannya. Materi yang dipergunakan dalam kegiatan ini diambil dari ujian kemampuan bahasa Jepang level 4 bagian dokkai (pemahaman bacaan). Penelitian ini menggunakan pendekatan kolaboratif, dimana kegiatan dibagi menjadi grup atau kelompok dalam menyelesaikan permasalahan. Pembelajaran kolaboratif digunakan agar setiap anggota kelompok ikut aktif dalam memberikan ide atau gagasannya terhadap permasalahan yang terjadi. Hasil dari kegiatan PkM ini adalah adanya masukan kata bahasa Indonesia dari satu kata bahasa Jepang, khususnya untuk katakata yang mempunyai unsur budaya. Kesepakatan dan keberterimaan kata yang dipakai menjadi poin penting dalam kegiatan pengabdian ini.
\end{abstract}

Kata Kunci: kolaboratif, MGMP, penerjemahan 
Rainhard Oliver Hoftman, Anggiarini Arianto, Siti Nur Isnaini, Rosi Novisa Syarani, \& Yanti Hidayati

\section{A. Pendahuluan}

Penerjemahan merupakan kemampuan produktif yang harus dimiliki oleh para pembelajar bahasa. Penguasaan kosakata yang baik dan kebiasaan membaca serta menulis merupakan tahapan penting dalam penerjemahan. Kebiasaan-kebiasaan untuk membaca berbagai bidang ilmu akan memperkaya pengetahuan yang dapat bermanfaat dalam kegiatan penerjemahan. Dalam penerjemahan bahasa Jepang, materi-materi disampaikan dengan menggunakan huruf kana sehingga penguasaan huruf mutlak harus dikuasai. Buku atau materi yang dipergunakan dalam mengajar pada level dasar bahasa Jepang sudah menggunakan huruf-huruf Jepang. Hiragana, katakana, dan kanji sudah mulai diajarkan di sekolah-sekolah menengah atas yang mempunyai mata pelajaran bahasa Jepang. Percakapan yang terdapat dalam buku tersebut juga sudah menggunakan bahasa Jepang.

Kesulitan-kesulitan para pengajar bahasa Jepang adalah ketika ada kondisikondisi budaya yang harus diterjemahkan akan tetapi padanan kata budaya tersebut tidak terdapat di budaya Indonesia. Diperlukan pemahaman yang memadai untuk menjelaskan kondisi seperti ini ketika mengajar atau mendapatkan pertanyaan dari anak didik. Kata-kata seperti itadakimasu, itte kimasu, dan itte irasshai. Kata-kata tersebut diterjemahkan menjadi selamat makan, saya pergi, saya datang. Kata-kata seperti di atas merupakan kata-kata budaya yang diterjemahkan sesuai dengan kegiatan yang dilakukan, budaya di Indonesia sendiri ketika akan makan tidak mempergunakan salam makan. Begitupun ketika kita akan pergi dan kembali lagi ke rumah atau kantor, biasanya mempergunakan kata assalammualaikum yang merupakan bahasa Arab, mengingat bahwa Indonesia merupakan negara mayoritas muslim.

Dari uraian permasalahan di atas, kegiatan pengabdian masyarakat kepada guruguru sekolah menengah atas di Jabodetabek dan Cirebon, diharapkan dapat menjawab dan memberikan pengertian yang mendalam terhadap anak-anak didiknya yang sedang mempelajari bahasa Jepang. Teori tentang penerjemahan ini, perlu diketahui dan dipahami oleh guru-guru pengajar bahasa Jepang, karena buku-buku dan materi yang dipergunakan di sekolah sudah menggunakan huruf kana dan membutuhkan penjelasan dari guru pengajar. Para ahli penerjemahan yang menawarkan beberapa definisi atas penerjemahan, namun pada hakikatnya penerjemahan merupakan pengalihan bahasa sumber (Bsu) ke dalam bahasa sasaran (Bsa) sesuai dengan makna yang dikandung dalam bahasa sumber.

Penerjemahan sebagai kegiatan mengalihkan makna suatu teks ke dalam bahasa lain sesuai apa yang dimaksud oleh pengarang (Newmark, 1988). Lebih khusus lagi Hatim dan Mason memandang penerjemahan sebagai bentuk komunikasi (Card et al., 1999). Setiap terjemahan dimaksudkan untuk mengatasi kesenjangan komunikasi antara penulis teks bahasa sumber dan teks bahasa sasaran. Penerjemahan melibatkan dua bahasa, yakni bahasa sumber dan bahasa sasaran. Penerjemahan bukan sekadar mengganti teks dalam satu bahasa (bahasa sumber) dengan bahasa lainnya (bahasa sasaran), melainkan mengalihkan pesan yang ada dalam sebuah teks sumber sehingga wajar dan dapat diterima dalam bahasa sasaran sehingga menghasilkan efek yang sama dengan yang dihasilkan teks sumber. Namun, karena

ACITYA BHAKTI, Volume 2 Nomor 1, Februari 2022 
bahasa merupakan bagian dari kebudayaan maka penerjemahan tidak saja bisa dipahami sebagai pengalihan bentuk dan makna, tetapi juga budaya.

Ketika menerjemahkan, penerjemah memerlukan strategi yang digunakan untuk memecahkan permasalahan penerjemahan. Permasalahan penerjemahan yang dimaksud adalah perbedaan budaya, perbedaan struktur kalimat, dan pemilihan kata. Strategi yang digunakan dipilih berdasarkan tujuan serta pembaca. Strategi penerjemahan yang ditawarkan oleh Vinay dan Darbelnet (Munday, 2016), yaitu:

1. Borrowing, teknik dengan cara mengambil dan membawa item BSu (Bahasa Sumber) ke dalam BSa (Bahasa Sasaran) tanpa modifikasi. Umumnya teknik ini digunakan untuk menerjemahkan istilah-istilah dalam bidang tertentu, misalnya komputer, obat-obatan, dan telekomunikasi.

2. Calque, teknik yang digunakan ketika suatu bahasa meminjam ekspresi bahasa lain kemudian menerjemahkannya secara harfiah masing-masing elemennya.

3. Literal translation, penggantian struktur sintaksis Bsu dengan struktur Bsa. Contohnya: Saya suka music = i like music .

4. Transposisi, Merupakan prosedur yang menggantikan elemen Bsu dengan elemen Bsa yang secara semantik sepadan namun tidak sepadan secara formal. Jenis pergeseran pertama adalah perubahan tunggal ke jamak. Kedua struktur gramatikal Bsu tidak dapat ditemukan dalam BSa. Ketiga yaitu pergeseran dilakuan ketika penerjemahan literal dapat dilakukan secara gramatikal tetapi tidak sesuai dengan penggunaan Bsa secara alami.

5. Modulasi, perubahan sudut pandang dan perspektif.

6. Equivalence, Merupakan prosedur yang mengganti sebagian Bsu dengan padanan fungsionalnya dalam BSa. Dengan kata lain situasi yang sama dapat diungkapkan ke dalam dua teks menggunakan metode stilistika dan struktural yang sama

7. Adaptasi Merupakan prosedur yang mengupayakan padanan kultural antara dua situasi tertentu. Teknik ini digunakan pada kasus pemadanan ketika situasi yang diacu oleh pesan dalam Bsu tidak dikenal dalam Bsa

Apakah dengan menggunakan prosedur di atas dapat menghasilkan terjemahan yang baik. Pertama, tentu kita harus mengetahui terlebih dahulu kategori terjemahan yang baik. Menurut Slepchenko (2014) dalam (Emzir, 2015) ada beberapa prinsip yang harus dipegang oleh si penerjemah agar menghasilkan terjemahan yang baik, yaitu.

1. Terjemahan harus merefleksikan makna teks sumber secara akurat.

2. Susunan kata dan ide terjemahan sedapat mungkin harus dekat dengan teks sumbernya (ini penting terutama dalam penerjemahan teks hukum, kontrak kerja sama, kartu garansi).

3. Pengaruh bahasa sumber. Hal yang kerap dikritisi terhadap terjemahan adalah "terjemahannya tidak natural" terjemahan yang baik dianggap sebagai terjemahan yang tidak setia pada bahasa sumbernya. 
Rainhard Oliver Hoftman, Anggiarini Arianto, Siti Nur Isnaini, Rosi Novisa Syarani, \& Yanti Hidayati

4. Gaya penulisan. Terjemahan harus mencerminkan gaya penulisan dari penulis aslinya.

5. Ekspresi idiomatikal. Idiom dianggap sebagai ekspresi yang tidak dapat diterjemahkan. Idiom tidak dapat diterjemahkan secara langsung. Triknya adalah jika tidak dapat diterjemahkan kembali menggunakan idiom dalam bahasa sasaran, jangan memaksanya.

Kualitas terjemahan bergantung pada kualitas penerjemah (pengetahuan, keterampilan, pelatihan, latar belakang budaya, keahlian. Penerjemah yang kompeten yang baik adalah (Newmark, 1988):

1. Kemampuan memahami bacaan dalam bahasa asing

2. Pengetahuan tentang subjek

3. Sensitivitas terhadap bahasa (baik BSu atau BSa)

4. Kompetensi menulis dalam bahasa target, jelas, efektif, dan kreatif.

Kegunaan penerjemahan bagi pembelajaran bahasa adalah (Emzir, 2015):

1. Membangkitkan diskusi kelas

2. Penerjemah mengembangkan tiga kualitas (fleksibilitas, akurasi, kejelasan) penting untuk pembelajaran bahasa, fleksibilitas (mencari kata-kata yang tepat, akurasi) dan menyampaikan apa yang dimaksud dengan jelas.

\section{B. Pelaksanaan dan Metode}

Kegiatan pengabdian kepada masyarakat ini menggunakan metode kolaboratif. Kolaboratif learning adalah bekerja bersama-sama dengan orang lain. Bekerja secara berpasangan atau dalam kelompok kecil untuk mencapai tujuan pembelajaran (Barkley, dkk, 2014, 4). Dengan metode yang digunakan ini, melahirkan beberapa pendapat dalam proses penerjemahan. Pendapat-pendapat tersebut disintesiskan kembali menjadi beberapa teori penerjemahan, dari kegiatan ini diperoleh kesimpulan yang tepat dalam menerjemahkan kata budaya. Proses pelaksanaan kegiatan ini awalnya diharapkan dapat dilaksanakan secara tatap muka namun, karena kondisi yang belum memungkinkan, maka kegiatan ini dilakukan dengan cara daring menggunakan zoom meetings. Namun demikian, hal yang baik dari kondisi ini adalah dapat menjangkau partisipan lebih jauh karena tidak ada batasan jarak dan waktu.

Kegiatan ini dilakukan untuk memahami sesuatu hal terkait penerjemahan dalam bahasa Jepang. Adapun terkait tempat, sasaran, dan waktu pelaksanaan pengabdian kepada masyarakat adalah sebagai berikut:

1. Tempat kegiatan : Rumah masing-masing guru SMA/SMK/Sederajat dan panitia.

2. Sasaran kegiatan : Guru-guru SMA/SMK/Sederajat di Jabodetabek dan Cirebon wilayah 3.

3. Kegiatan PkM ini melalui Zoom Meeting yang diselengarakan pada tanggal 12 Desember 2020, pukul 09.00 - 12.00 WIB. 
Kegiatan pelaksanaan PkM ini terdiri dari 3 tahap yaitu, pemberian materi dari dosen STBA JIA dan Dosen STIBA Invada, Workshop, dan Presentasi hasil diskusi.

$09.00-10.00$

presentasi dari dosen STBA JIA dan dosen STIBA Invada

$10.00-11.00$ workshop penerjemahan

$11.00-12.00$

presentasi dari peserta tentang materi penerjemahan.

Adapun uraian dari tiap tahapan pengabdian tersebut adalah sebagai berikut:

1. Pemberian Materi

Kegiatan ini dimulai dari pemberian materi oleh dua orang narasumber yang berasal dari dua instansi yaitu STBA JIA dan STIBA Invada. Pembicara pertama yaitu ibu Anggiarini Arianto, S.S, M.Hum yang memberikan materi tentang penerjemahan dan pengajaran bahasa. Bagaimanakah menerjemahkan yang baik?, strategi menerjemahkan, beberapa metode penerjemahan dari para ahli, dan teknik penerjemahan yang baik.

Pembicara kedua dari dosen STIBA Invada yaitu bapak M. Fahmi Reza, S.E, MIT, memberikan materi tentang "menjadi penerjemah lisan, bahasa Jepang itu keren". Materi yang disampaikan tentang pengalaman Fahmi sensei menjadi penerjemah lisan di berbagai bidang baik di lingkungan industri maupun dunia hiburan. Ada beberapa Teknik-teknik penerjemahan lisan yang disampaikan yaitu:

a. 同時通訳 - Simultaneous Interpreting yaitu penerjemahan secara langsung atau simultan ketika pembicara belum selesai berbicara, penerjemah sudah mulai untuk menerjemahkan kata-kata yang sudah diutarakan sebelumnya.

b. 逐次通訳 - Consecutive Interpreting yaitu penerjemahan yang dilakukan ketika pembicara sudah selesai berbicara.

c. 時差通訳 - Post record Interpreting yaitu metode penerjemahan yang biasanya digunakan untuk penerjemahan siaran untuk program berita regular di negara lain.

Beberapa poin penting dari materi ini adalah: penerjemah hanya sebagai corong atau penyampai pesan, alih bahasa dari bahasa sumber ke bahasa sasaran, bahasa yang menyinggung salah satu pihak disampaikan secara hatihati, namun demikian pesan yang sama dapat tetap tersampaikan, serta menjaga kerahasiaan dari klien tentang hal-hal yang merupakan rahasia perusahaan. Dalam penerjemahan lisan, terkadang banyak keluar kata-kata budaya yang tidak ada padanannya dalam bahasa Indonesia. Contohnya, kata itadakimasu yang jika diartikan menjadi selamat makan dalam bahasa Indonesia. Kata ini muncul ketika bertemu atau negosiasi bisnis di restoran, orang Jepang menggunakan kata ini sebelum mulai menyantap makanan.

2. Workshop.

Kegiatan selanjutnya setelah pemberian materi dan tanya jawab adalah pembagian kelompok. Dari 33 peserta yang mendaftar dibagi menjadi 4 
Rainhard Oliver Hoftman, Anggiarini Arianto, Siti Nur Isnaini, Rosi Novisa Syarani, \& Yanti Hidayati

kelompok untuk belajar menerjemahkan sebagian dari bacaan yang sudah disiapkan oleh fasilitator. Materi bacaan bahasa Jepang diambil dari https://www.szlonghe.com/h-nd-218.html nihongo no ryouku shiken $\mathrm{N}-4$ untuk dibahas oleh tiap peserta dan kegiatan dalam breakout room ini dipandu oleh 1 orang fasilitator. Materi bacaan yang dipakai yaitu:

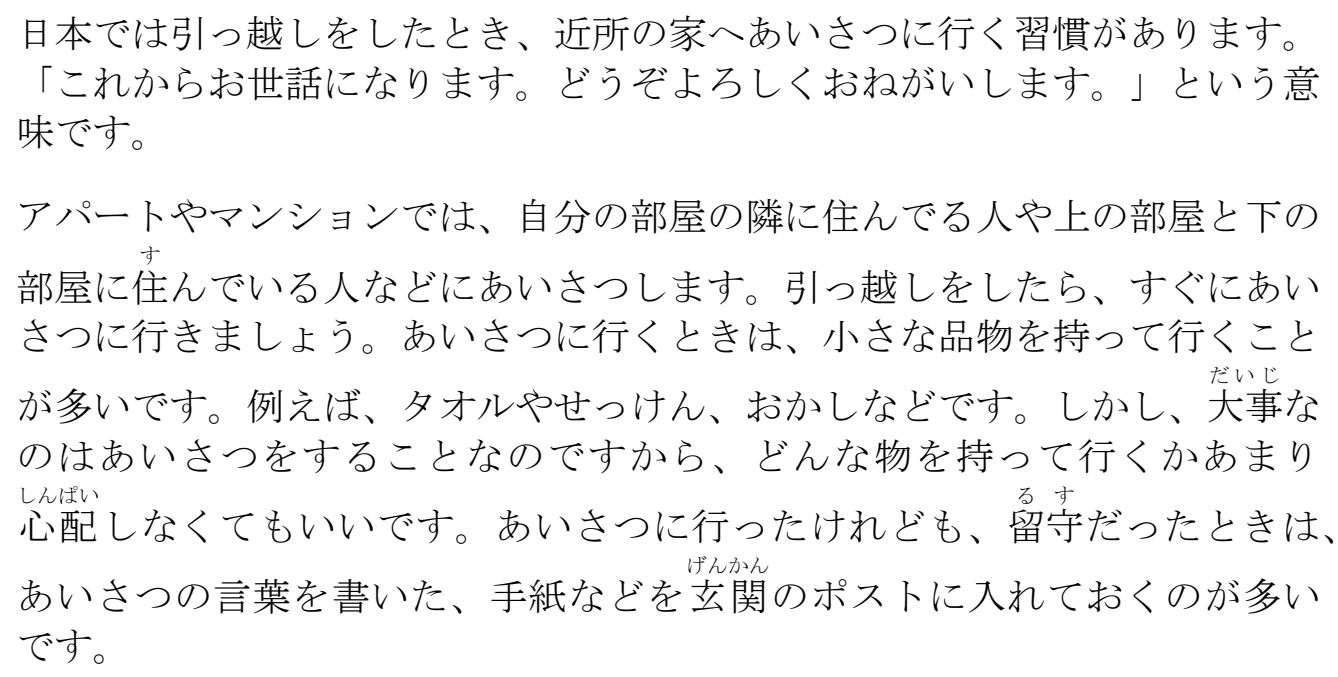

最近は、「引っ越しのあいさつ」をしない人も多くなっています。特に、一 人で住むときは、あいさつをしない人がたくさんいます。しかし、私は「引 つ越しのあいさつ」は、やはりいい習慣だと思います。

Setelah berdiskusi sekitar 15-20 menit, hasil penerjemahan dipresentasikan di room utama Zoom meeting.

3. Presentasi hasil diskusi

Presentasi hasil diskusi dari 4 kelompok dibahas dan dikomentari oleh narasumber maupun peserta untuk mendapatkan jawaban yang tepat dari materi yang diberikan. Hasil dari diskusi ini dipaparkan dalam Hasil dan Pembahasan.

\section{Hasil dan Pembahasan}

Kegiatan pengabdian ini berlangsung masih dalam suasana pandemi covid19, sehingga kegiatan menggunakan zoom meeting untuk berinteraksi. Para peserta sangat antusias mengikuti semua tahapan dalam kegiatan ini. Terdapat 33 peserta dari sekolah-sekolah menengah atas yang ikut serta dalam kegiatan ini. 8 sekolah dari daerah Bekasi dan sisanya 25 sekolah dari wilayah Cirebon. Tujuan dari kegiatan ini adalah menambah pengetahuan tentang penerjemahan dan stimulus untuk guru-guru membuat bahan ajar yang menarik untuk peserta didik, dapat menerjemahkan buku-buku yang dipakai dalam pengajaran agar tidak salah dalam pemberian materi kepada peserta didik. 
日本では引つ越しをしたとき、近所の家へあいさつに行く習慣があります。 「これからお世話になります。どうぞよろしくおねがいします。」という 意味です。

"Nihon de hikkoshi wo shita toki, kinjou no ie he aisatsu ni iku shuukan ga arimasu. [korekara osewa ni narimasu. Douzo yoroshiku onegaishimasu]. To iu imi desu".

Penerjemahan grup 1 sampai 4, sebagai berikut:

1. Di Jepang saat pindah rumah ada kebiasaan memberi salam kepada tetangga. Artinya (dari sekarang mohon bantuannya, mohon diterima).

2. Di Jepang saat pindah rumah terdapat kebiasaan pergi untuk berkenalan ke rumah tetangga. Salam yang dipergunakan yaitu: korekara osewani narimasu. Douzo yoroshiku onegaishimasu.

3. Di Jepang waktu pindah rumah, terdapat kebiasaan pergi untuk berkenalan ke rumah tetangga. Mulai sekarang, mohon bantuannya.

4. Di Jepang pada saat pindah rumah, ada kebiasaan untuk berkunjung ke rumah tetangga. "mulai sekarang saya akan butuh pertolongan anda. Senang berkenalan dengan anda".

Dari keempat hasil diskusi terdapat perbedaan ketika menerjemahkan kata budaya korekara osewani narimasu, douzo yoroshiku onegaishimasu. Kelompok pertama menerjemahkan semua kata ke dalam bahasa sasaran yaitu bahasa Indonesia. Kata aisatsu yang berarti salam tetap digunakan sesuai dengan terjemahannya. Penerjemahan ini dikomentari oleh kedua narasumber dan hasilnya cukup berterima.

Penerjemahan kelompok kedua, untuk kata budayanya tidak diterjemahkan ke dalam bahasa sasaran, tetap menggunakan bahasa Jepang. Komentar dari kedua narasumber adalah sebaiknya tetap diterjemahkan dengan menggunakan kata-kata yang berterima di bahasa sasaran. Hasil dari kelompok tiga, kata "aisatsu"diterjemahkan menjadi "berkenalan". Komentar dari kedua narasumber kata tersebut juga berterima. Kelompok terakhir semua kalimat diterjemahkan ke dalam bahasa sasaran dan kata "aisatsu ni iku" diterjemahkan menjadi "berkunjung", komentar dari kedua narasumber untuk hasil penerjemahan kelompok empat dianggap yang paling berterima.

Penjelasan di atas dapat dilihat pada tabel di bawah ini:

Tabel 1. Penerjemahan kata budaya

\begin{tabular}{|c|c|c|c|c|c|c|}
\hline Kata & Kel 1 & Kel 2 & Kel 3 & Kel 4 & Hasil & Strategi \\
\hline Aisatsu & salam & & & & berterima & Equivalence \\
\hline
\end{tabular}


Rainhard Oliver Hoftman, Anggiarini Arianto, Siti Nur Isnaini, Rosi Novisa Syarani, \& Yanti Hidayati

\begin{tabular}{|c|c|c|c|c|c|c|}
\hline & & berkenalan & & & berterima & Equivalence \\
\hline & & & berkenalan & & berterima & Equivalence \\
\hline & & & & berkunjung & berterima & Adaptasi \\
\hline $\begin{array}{l}\text { korekara } \\
\text { Osewa ni } \\
\text { narimasu }\end{array}$ & $\begin{array}{l}\text { Dari } \\
\text { sekarang } \\
\text { mohon } \\
\text { bantuann } \\
\text { ya } \\
\end{array}$ & & & & berterima & Adaptasi \\
\hline & & $\begin{array}{l}\text { Tidak } \\
\text { diterjemah } \\
\text { kan }\end{array}$ & & & $\begin{array}{l}\text { Kurang } \\
\text { berterima }\end{array}$ & Borrowing \\
\hline & & & $\begin{array}{l}\text { Mulai } \\
\text { sekarang } \\
\text { mohon } \\
\text { bantuanny } \\
\text { a } \\
\end{array}$ & & berterima & Adaptasi \\
\hline & & & & $\begin{array}{l}\text { Mulai } \\
\text { sekarang } \\
\text { saya akan } \\
\text { butuh } \\
\text { pertolonga } \\
\text { n }\end{array}$ & berterima & Adaptasi \\
\hline
\end{tabular}

Tabel 1 di atas merupakan kesimpulan yang didapat dari hasil PkM tentang penerjemahan. Dari penerjemahan yang diberikan terdapat 1 kata dan 1 ungkapan budaya yang diterjemahkan bervariasi oleh peserta. Kata aisatsu diterjemahkan menjadi salam, berkenalan, dan berkunjung. Ketiganya dinyatakan berterima, strategi yang digunakan yaitu equivalence, adaptasi, dan borrowing. Ungkapan budaya korekara osewa ni narimasu juga diterjemahkan bervariasi dan semuanya berterima, strategi yang digunakan yaitu adaptasi.

Gambar 1. Kegiatan PkM Penerjemahan

ACITYA BHAKTI, Volume 2 Nomor 1, Februari 2022 


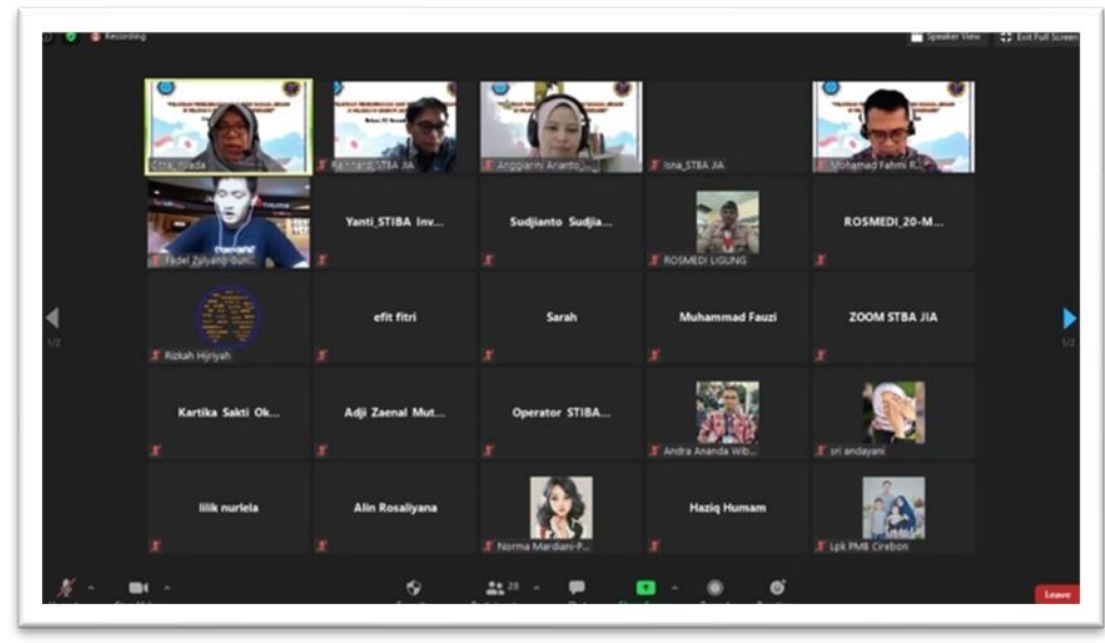

Gambar 2. Tanya Jawab oleh Peserta PkM

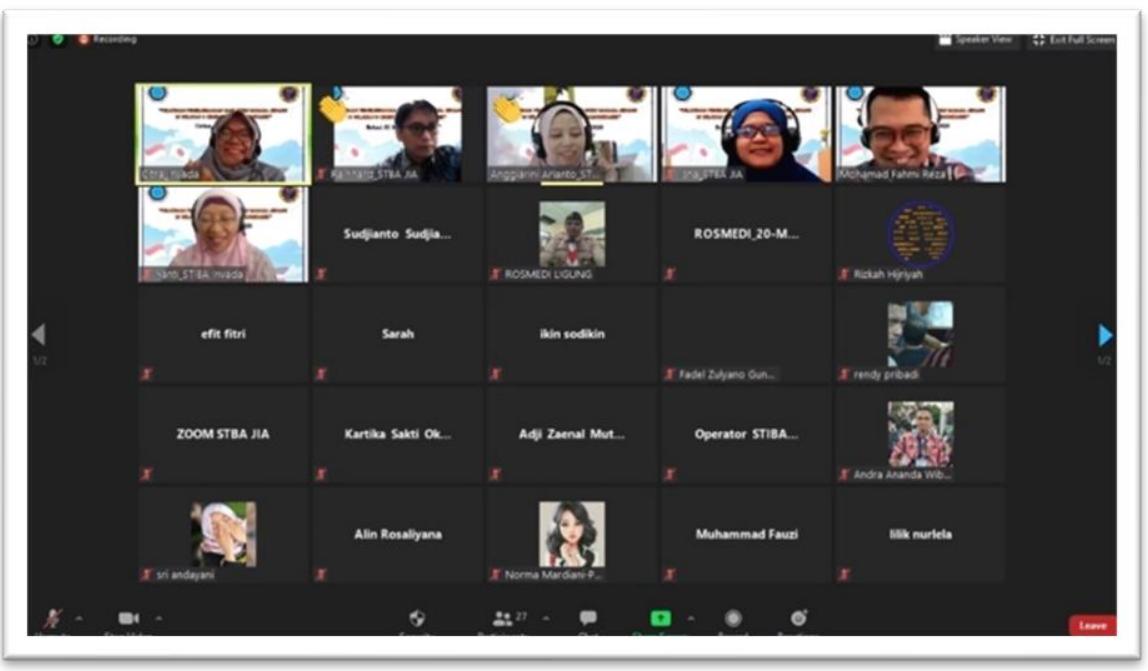

Gambar 1 di atas

penerjemahan. Pengalaman dan materi yang belum dipahami oleh peserta ditanyakan langsung kepada narasumber.

\section{Penutup \\ Simpulan}

Dari kegiatan yang telah diselenggarakan dapat disimpulkan, bahwa kegiatan pengabdian masyarakat yang melibatkan guru-guru bahasa Jepang tentang penerjemahan masih perlu untuk ditingkatkan. Dari hasil kegiatan terlihat masih ada bagian-bagian penerjemahan yang belum dikuasai oleh beberapa peserta. Seperti, kala, tenses, dan penerjemahan budaya. Dalam penerjemahan budaya sebaiknya tetap diterjemahkan untuk memberikan pengetahuan tentang kata-kata yang dipakai dalam berinteraksi dengan penutur asing. Strategi penerjemahan yang dihasilkan dari kegiatan ini adalah equivalence, adaptasi, dan borrowing. Kata-kata budaya yang terdapat pada buku teks bahasa Jepang untuk siswa sekolah menengah atas atau sederajat dapat menjadi masukan atau informasi 
Rainhard Oliver Hoftman, Anggiarini Arianto, Siti Nur Isnaini, Rosi Novisa Syarani, \& Yanti Hidayati

ketika memberikan materi pengajaran kepada peserta didik. Peserta didik yang mempelajari bahasa Jepang dapat memahami situasi dan kondisi ketika menggunakan kata-kata budaya dalam bahasa Jepang. Kata-kata seperti itadakimasu, yoroshiku onegaishimasu, dan osewani narimasu dapat dipergunakan siswa dengan tepat ketika berlatih atau bercakap-cakap menggunakan bahasa Jepang.

Faktor-faktor pendukung dari kegiatan ini adalah antusias pemateri dan peserta terhadap pembelajaran bahasa Jepang. Terbukti dari banyaknya peserta yang ikut dalam kegiatan pengabdian masyarakat ini. Dalam kegiatan ini terdapat juga faktor atau kondisi yang membuat kegiatan sedikit terhambat yaitu sinyal disetiap daerah yang masih dirasa kurang bersahabat. Ada peserta dan fasilitator yang mengalami sinyal yang kurang baik, sehingga penyampaian atau tanya jawab kurang maksimal. Bahasan materi tidak semua tersampaikan karena keterbatasan waktu, sehingga kesimpulan penerjemahan dari materi disampaikan secara lisan oleh kedua pemateri.

\section{Saran}

Kegiatan serupa harus terus dilaksanakan dan dikembangkan untuk memberikan informasi terkait penerjemahan dan pengajaran bahasa Jepang secara umum. Kondisi pandemi tidak membuat kegiatan PkM atau pengajaran menjadi berhenti melainkan dapat terciptanya inovasi atau pemikiran baru agar ilmu pengetahun dapat terus tersampaikan.

\section{Ucapan Terima Kasih}

Terima kasih kepada STBA JIA, STIBA Invada, dan terlebih para peserta guru-guru maupun pemerhati bahasa dari Jabodetabek dan Cirebon atas partisipasi dalam keberlangsungan kegiatan ini.

\section{DAFTAR PUSTAKA}

Arianto, A. (2017). Penerjemahan onomatopea dan mimesis dari bahasa jepang ke dalam bahasa indonesia. Thesis.

Card, L., Hatim, B., \& Mason, I. (1999). The translator as communicator. language. https://doi.org/10.2307/417507

Barkley. E. E., Cross, K. P., \& Major, C. H. (2014). Collaborative learning techniques. Nusa Media.

Emzir. (2015). Teori dan pengajaran penerjemahan ( $1^{\text {st }}$ ed). Rajawali Pres

Hatim, B., \& Ian, M. (1997). The translator as communicator. Routledge.

Larson, M. (1989). Penerjemahan berdasar makna: pedoman untuk pemadanan antar bahasa. Arcan.

Machali, R. (2009). Pedoman umum bagi penerjemah. Mizan Pustaka.

ACITYA BHAKTI, Volume 2 Nomor 1, Februari 2022 
Mountaha, S. (2006). Bahasa dan terjemahan. Ksaint Blanc.

Munday, J. (2016). Introducing translation studies: Theories and applications. https://doi.org/10.4324/9781315691862.

Newmark, P. (1988). A Textbook of Translation. Prentice Hall.

Nida, E. A., \& Taber, C. R. (1974). The theory and practice of translation. https://www.szlonghe.com/h-nd-218.html 